\title{
Thrombo-Embolic Events in Cancer Patients with Impaired Renal Function
}

Elalamy I*, Canon JL, Bols A, Lybaert W, Duck L, Jochmans K, Bosquée L, Peeters M, Awada AH, Clement P, Holbrechts S, Baurain JF, Mebis $\mathrm{J}$ and Nortier $\mathrm{J}$

Department of Thrombosis Center, CHU Tenon, Rue de la Chine 4, 75020 Paris, France

\begin{abstract}
Venous Thromboembolism (VTE) is a frequent cause of mortality and morbidity in patients with malignancy. Thrombosis is one of the leading causes of death in patients with malignancy after cancer itself. As such, prompt recognition and treatment of VTE are required in order to reduce the risk of VTE-related mortality. This report reviews the interrelationship between cancer, renal insufficiency and VTE. The working group behind this review article concludes that Low Molecular Weight Heparins (LMWHs) decrease the risk of recurrent venous thrombosis in cancer patients without increasing major bleeding complications. LMWHs are therefore recommended as first line antithrombotic treatment in cancer patients with a clear clinical benefit. In patients with renal dysfunction, who are at both increased risk of bleeding and of thrombotic complications, preference should be given to unfractionated heparin or a LMWH with a mean molecular weight such as tinzaparin, having less risk of plasma accumulation and offering the possibility to maintain full therapeutic dose.
\end{abstract}

Keywords: Venous thromboembolism; Cancer; Renal impairment; Low molecular weight heparin

\section{The Relationship between Cancer and Thrombosis}

There is a mutual relationship between cancer and thrombosis: cancer predisposes to thrombosis, and the evolution of the oncological process is linked to this acquired hypercoagulable state. Risk of venous thrombo-embolic disease is significantly increased in cancer patients (Relative Risk 3 to 6) [1]. On the other hand, even silent abnormal hemostasis has a negative impact on disease progression and associated morbidity and mortality. Solid tumours, particularly of the pancreas, colon, ovary, brain and lung, are prone to generate thrombo-embolic events [2,3]. Metastatic disease further increases this risk, and this effect is even more pronounced during chemotherapy or radiotherapy [4]. Thrombin generation, as a result of a cascade of activated coagulant proteases, plays a key role in the evolution of cancer. Thrombin induces fibrin formation, creating tumour cell lodges known to promote tumour cell survival and metastatic colony formation $[5,6]$. Thrombin activates protease-activated receptor 1 (PAR1), contributing to tumour cell growth, invasion and angiogenesis through different mechanisms that are not completely unravelled yet.

All the aspects of the triad of Virchow already described in 1863 are frequently present in cancer patients [7].

- Hyper coagulability due to both the inflammatory state, FVIII increase, Tissue Factor (TF) over expression, acquired resistance to activated protein $\mathrm{C}$, etc.

- Endothelial dysfunction, linked to the prothrombotic impact of tumour cell cytokines, chemotherapy, catheter or surgery induced vascular lesions and multi cellular activation.

- Venous stasis, often due to immobilization during hospitalization, besides venous compression due to tumour expansion or adenopathies.

Various pro-coagulant factors encountered in patients with cancer are depicted in Figure 1.

Interactions between endothelial cells and tumour cells generate micro particles and cellular hetero-complexes through p-select in bridges. These particles protect tumour cells in the blood circulation against immune NK cell cytotoxic activity through shielding by a socalled storehouse, made of a fibrin-platelets-leukocytes coat acting as a bush-like clot shield. Several mediators are typically involved in this cellular network such as inflammatory cytokines (e.g. TNFa, Tumor Necrosis Factor) and oncogenic factors with vascular impact (e.g. VEGF, Vascular Endothelial Growth Factor), as well as classical coagulation cascade actors such as tissue factor and thrombin $[5,6]$. Tissue factor and thrombin interact with the tumour cell membrane, and contribute to tumoral shape change, proliferation, Epithelial Mesenchymal

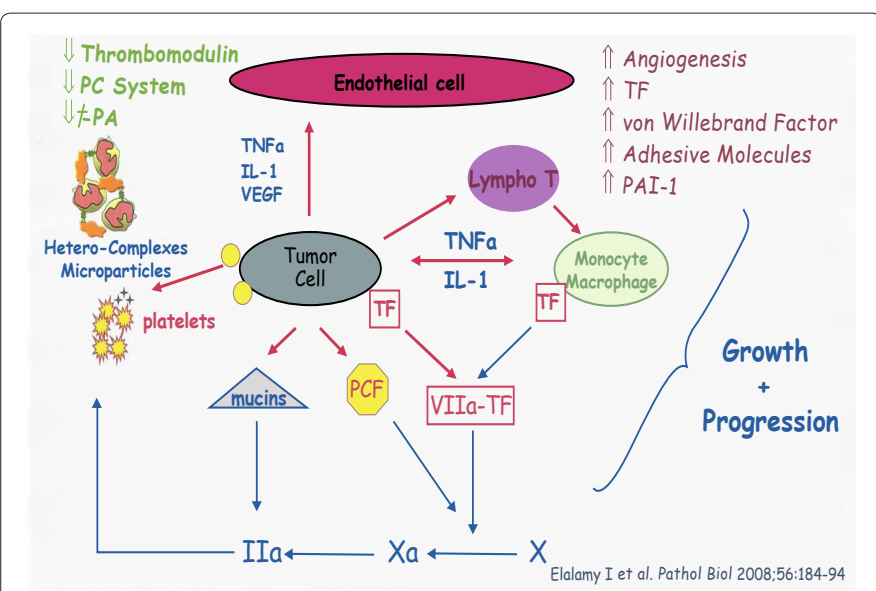

Figure 1: Procoagulant factors observed in patients with cancer.

*Corresponding author: Elalamy I, Professor of Hematology and Director of Hematology, Department of Thrombosis Center, CHU Tenon, Paris, Rue de la Chine 4, 75020 Paris, France, Tel: +33 (0)1 560170 00; E-mail: ismail.elalamy@tnn.aphp.fr

Received January 23, 2014; Accepted March 17, 2014; Published March 23 , 2014

Citation: Elalamy I, Canon JL, Bols A, Lybaert W, Duck L, et al. (2014) Thrombo-Embolic Events in Cancer Patients with Impaired Renal Function. J Blood Disorders Transf 5: 202. doi: 10.4172/2155-9864.1000202

Copyright: @ 2014 Elalamy I, et al. This is an open-access article distributed under the terms of the Creative Commons Attribution License, which permits unrestricted use, distribution, and reproduction in any medium, provided the original author and source are credited. 
Transition (EMT), adhesion and metastatic cell migration through the vascular wall, and proteolysis of surrounding tissue. Thrombin is a potent activator of tumor angiogenesis and metastatic process through membrane protease-activated receptors PAR-1, PAR-3 and PAR-4, together with G-proteins regulation. TF activates vascular remodeling through various kinases (MAP kinase, P38) and particular oncogenes. It also promotes angiogenesis through VEGF secretion and malignancy progression, and therefore participates actively in micro-environmental changes around the tumour.5The complex TFVIIa has anti-apoptotic effects and induces angiogenetic regulatory mechanism. The fibrinolytic system is out of balance as tumour cells secrete various factors such as tissue-type plasminogen activator (tPA) and plasminogen activator inhibitors PAI-1 and PAI-2. Platelets are also important in this complex process [5]. An increased platelet count is associated with a worse cancer prognosis, whereas platelet depletion has a relative anti metastatic effect.

Low Molecular Weight Heparins (LMWHs) are a heterogeneous group of heparin polysaccharides obtained by fractionation of the natural mastocyte-extracted heparin, thereby exerting their anticoagulant activity largely through the mandatory pentasaccharidebinding domain interaction with antithrombin. This enhances the inhibitory effect of anti thrombin on activated factor X (FXa), thrombin (or activated factor II, FIIa) activated factor IX and activated factor XII, to variable extent for each factor according to the different chain molecular weight [8]. They also act on regulation through stimulation of the release of endothelial tissue factor pathway inhibitor (TFPI), and also in part through inhibition of factor VIIa, again according to their structural characteristics and their molecular weight [8]. For example, TFPI release was reported to be in the order of magnitude of $7000 \mathrm{ng} /$ $\mathrm{ml} / 2.10^{5}$ cells with tinzaparin (Molecular Weight $\mathrm{MW}=6750 \mathrm{Da}$ ) and in the range of $4000 \mathrm{ng} / \mathrm{mL} / 2.10^{5}$ cells with enoxaparin $(\mathrm{MW}=4200 \mathrm{Da})$ ornadroparin (MW=4500 Da) [9]. Another example is illustrated in Table 1, showing the heterogeneous effects of the various LMWHs on FXa and FIIa, according to their respective molecular weight [10].

Unfractionated or natural heparin (UFH) has an effect of equal intensity on FXa and on thrombin (FIIa). Tinzaparin and dalteparin have the highest molecular weights and therefore the longest polysaccharide chains. This gives the man anticoagulant profile closer to natural heparin (UFH), including a more pronounced anti-IIa effect. Because of that, tinzaparin was the closest to UFH for inhibiting thrombin activity, as shown on in Figure 2 [10]. At a concentration of 0.2 anti-Xa IU/mL tinzaparin and UFH already decreased the propagation rate index of thrombin generation by approximately $60 \%$ compared to control $(\mathrm{p}<0.05)$. This was much less pronounced with the other compounds, unless their anti-Xa activity and inherent concentration was increased at least threefold [10].

As depicted in Figure 3, several clinical trials have been performed comparing LMWH with either vitamin K antagonists (VKA, coumarin

\begin{tabular}{|l|c|c|c|}
\hline Heparin & Mean MW (Da) & Anti-Xa / anti-Ila & Anti Xa activity /mg \\
\hline UFH & 15000 & 1 & $193 \mathrm{U}$ \\
\hline Tinzaparin & 6500 & 2 & $90 \mathrm{IU}$ \\
\hline Dalteparin & 6000 & 2,5 & $130 \mathrm{IU}$ \\
\hline Enoxaparin & 4500 & 3,9 & $100 \mathrm{IU}$ \\
\hline Nadroparin & 4200 & 3,5 & $95-130 \mathrm{IU}$ \\
\hline Reviparin & 3800 & 3,25 & $106 \mathrm{IU}$ \\
\hline Bemiparin & 3600 & 8 & $80-100 \mathrm{IU}$ \\
\hline
\end{tabular}

Table 1: Heterogeneous effects of the various LMWHs on FXa and Flla, according to their respective molecular weight [10] derivatives) or UFH [11]. It can be concluded from a meta-analysis of such studies that LMWH-treated patients experience significantly less recurrent venous thrombotic events than those treated with VKA. Even hemorrhagic complications tended to be lower with LMWH when compared with vitamin $\mathrm{K}$ antagonists [11].

Comparisons of LMWH and UFH were also performed, and the main results are shown in Figure 4 [12]. These data indicate a 61\% clear and significant reduction of thrombo-embolic events in favour
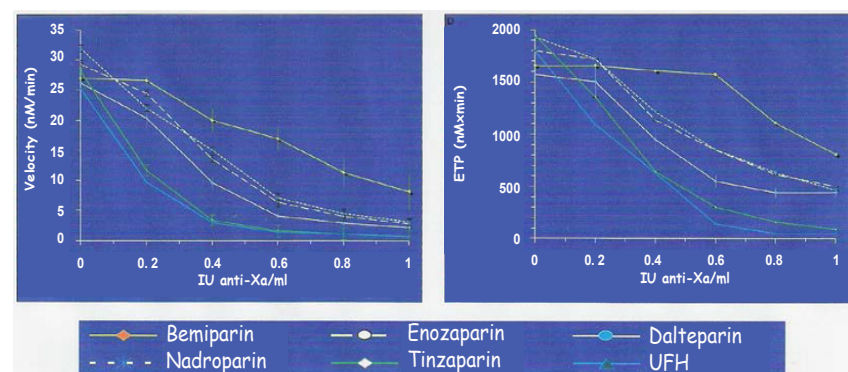

Figure 2: Tinzaparin is closest to UFH for inhibiting thrombin activity of all LMWHs [10].

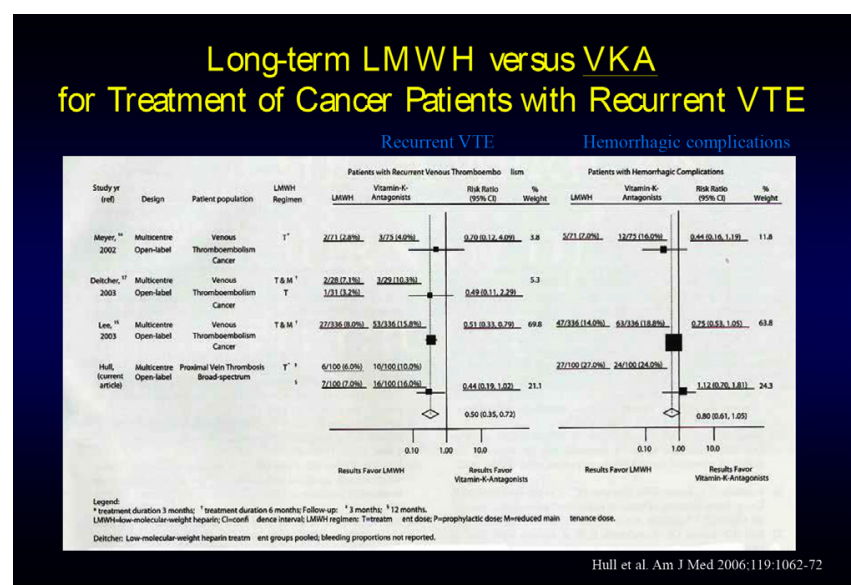

Figure 3: Meta-analysis of clinical trials comparing LMWHs with VKA in the management of recurrent VTE in patients with cancer [11].

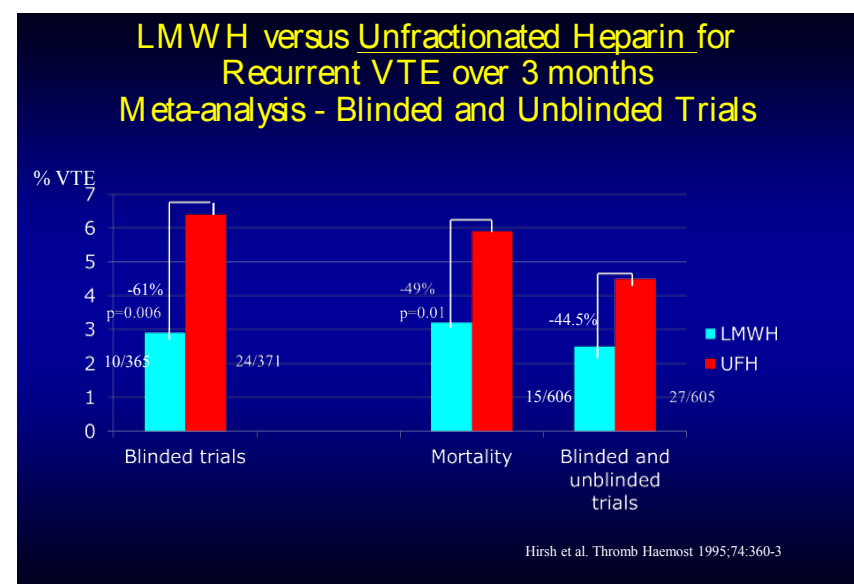

Figure 4: Meta-analysis of studies comparing LMWH with unfractionated heparin in the management of recurrent VTE. 
of LMWH use [12]. Major bleeding episodes occurred significantly less frequently (58\%) with LMWH [12].

It is therefore logical that most international guidelines (ACCP ASCO-ESMO) globally recommend the use of LMWH or fondaparinux or unfractionated heparinas an initial treatment in case of a venous thrombo-embolic event in cancer patients. For a long-term treatment, LMWHs are also recommended for 3 to 6 months particularly in cancer patients. Vitamin K antagonists can be used if LMWH are not tolerated or contra-indicated. Importantly, in case of active cancer indefinite continuation of anticoagulation is recommended in high risk patients [13-15].

\section{Cancer Patients, Use of LMWH and Renal Impairment}

The BIRMA trial reported a $64 \%$ prevalence of renal dysfunction (Glomerular Filtration Rate [GFR] lower than $90 \mathrm{~mL} / \mathrm{min}$ ) in Belgian cancer patients [16]. On the other hand; the same study showed that many anticancer treatment combinations used had also potentially nephrotoxic effects [16]. This fact together with the mainly renal elimination of most implies that even a GFR of $90 \mathrm{~mL} / \mathrm{min}$ should be considered with caution, as nephrotoxicity of chemotherapeutic agents tends to increase with decreasing renal function. They may also possibly accelerate the spiral of renal damage and consequently increase the risk of LMWH accumulation with an increased associated bleeding risk.

Is the uncorrected serum creatinine (s-creatinine) determination a reliable test for assessing renal dysfunction profile in these patients? The answer is no, as shown in the main IRMA study in France [17]. Indeed, $65 \%$ of patients with so called "normal s-creatinine" levels had a GFR below $90 \mathrm{~mL} / \mathrm{min}$. The risk of missing a renal dysfunction diagnosis remains therefore a frightening reality when the clinician solely relies upon standard s-creatinine measurements [17].

How do LMWHs behave in case of renal dysfunction? There is a well-established correlation between LMWH molecular weight and its excretion. The higher the weight, the more the LMWH is excreted through the reticulo-endothelial system, and not through the kidney route [18]. This has significant implications upon the in vivo pharmacokinetic behavior of the different LMWH compounds, as shown in Figure 5 [19].

These data have shown that only tinzaparin has an unchanged apparent half-life when renal function declines as far as to $20 \mathrm{~mL} / \mathrm{min}$ [18]. Other LMWHs, such as enoxaparin or dalteparindo show a degree of drug accumulation as the apparent half-life increases with lowerrenal filtration, especially when usual therapeutic doses are maintained in this type of patients $[18,19]$. For nadroparin, an accumulation of antiXa activity, but not of anti-IIa effects, was reported in elderly patients with mild to moderate renal impairment (GFR: $62 \pm 6 \mathrm{~mL} / \mathrm{min}$ ). The correlation between anti-Xa activity and creatinine clearance was statistically significant (correlation coefficient $0.49 ; \mathrm{p}<0.002$ ) which was not the case for anti-IIa activity (correlation coefficient $0.03 ; \mathrm{p}=0.87$ ) $[19,20]$.

Does these haveany clinical implications? A French study involving 52 elderly patients with a mean GFR $34.7 \mathrm{~mL} / \mathrm{min}$ (range $20-50 \mathrm{~mL} / \mathrm{min}$ ) reported an increased amount of available enoxaparin activity (given at 4000 IU od) after 8 days of sub-coetaneous administration, expressed

\section{Kinetics of LMWH in Renal Dysfunction}
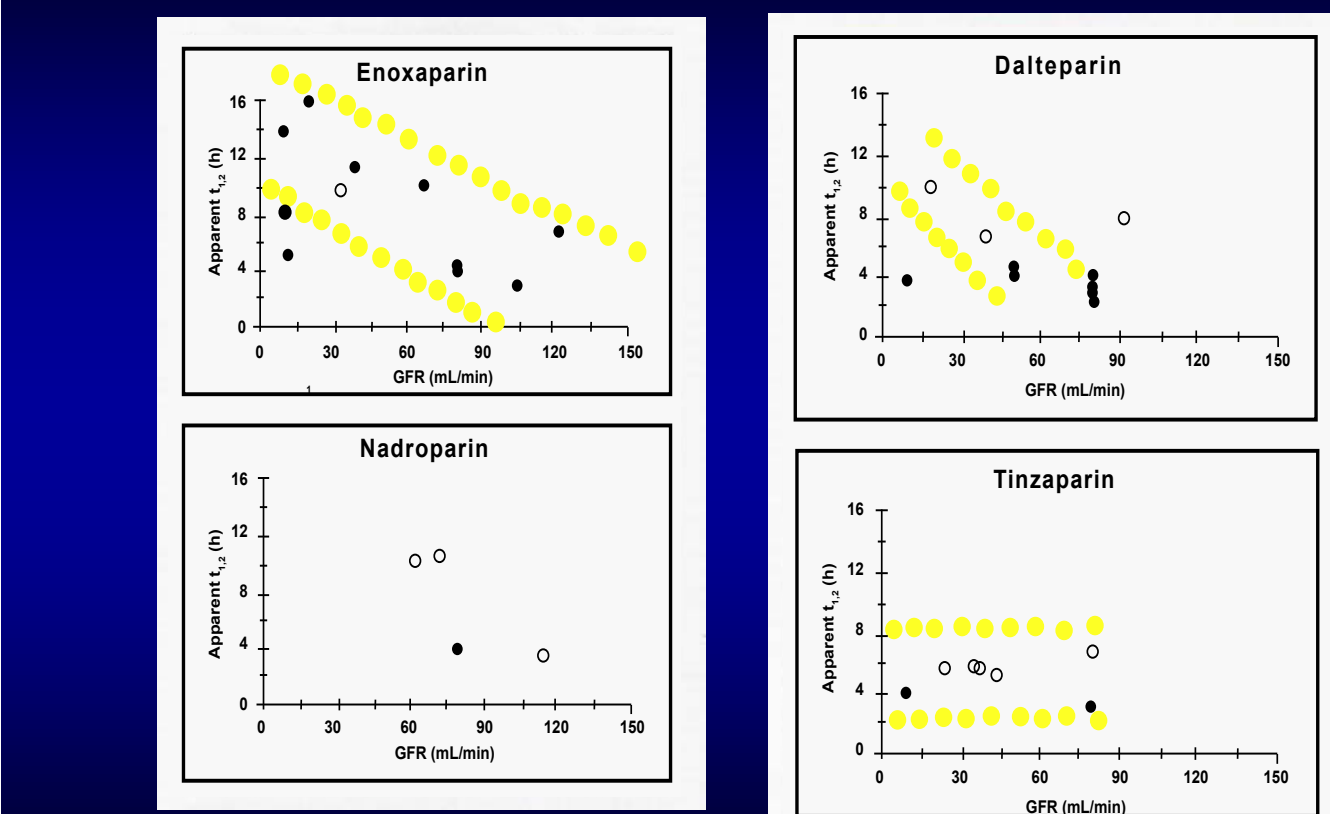

Schmid et al. Swiss Med Wkly 2009;139:438-52

Figure 5: Kinetics of LMWHs in patients with renal impairment [17] 


\section{Effect of Tinzaparin on Recurrent Venous Thrombo-embolism in Cancer Patients}

\section{LITE Cancer Trial : 3 Months \\ ; 12 M onths data}
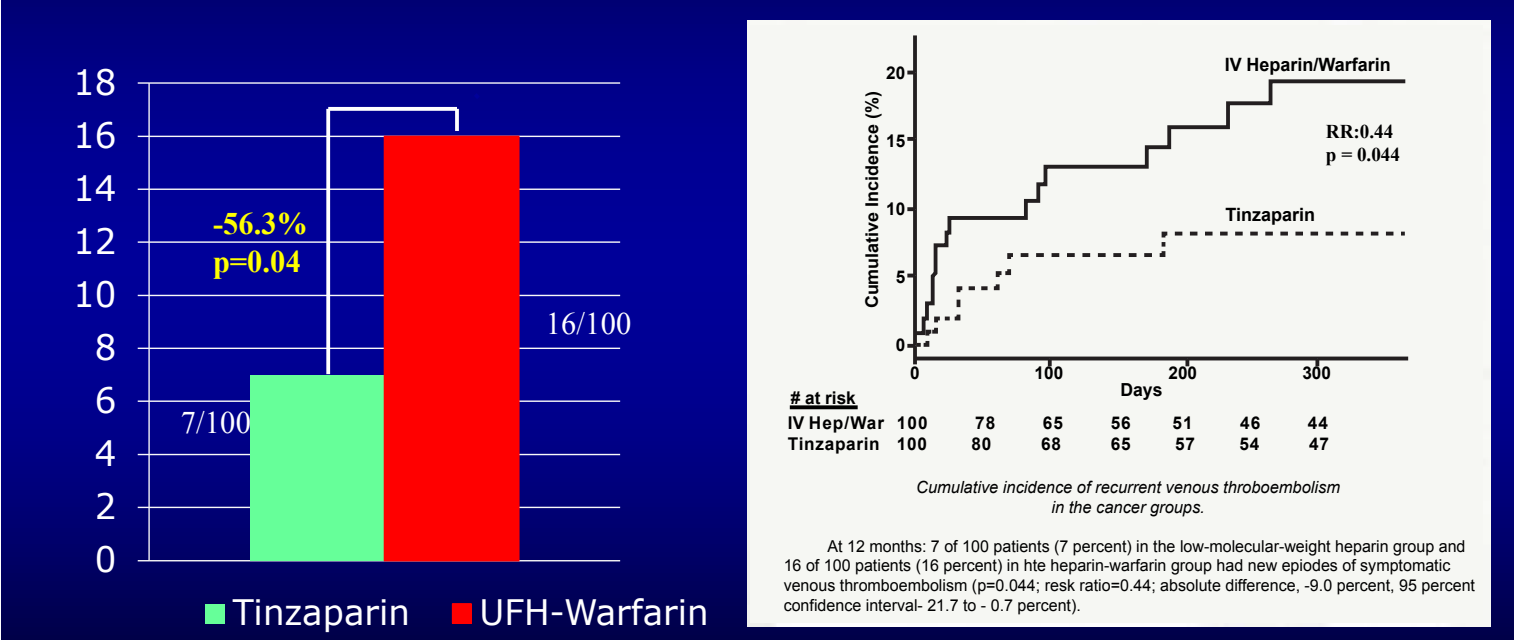

$\mathrm{N}=200$

Tinzaparin $175 \mathrm{IU} / \mathrm{kg} / \mathrm{day}$

Exclusion: Haemodialysis dependent

Figure 6: The effect of tinzaparin on recurrent VTE in cancer patients as seen in the LITE trial [11].

as Area Under the Curve $(\mathrm{p}<0.001)$ [21]. In contrast, with tinzaparin (given at $4500 \mathrm{IU}$ od) no signs of accumulation were observed. In another study, 30 patients were very old and had a mean GFR of 40.6 $\mathrm{mL} / \mathrm{min}$ (range $20-72 \mathrm{~mL} / \mathrm{min}$ ) [22]. Tinzaparin given at full doses of 175 anti-Xa IU/kg did not appear to induce any accumulation, even in patients with the lowest GFR range $(20-29 \mathrm{~mL} / \mathrm{min})$. There was no progressive increase of plasma anti-Xa or anti-IIa activities. Neither thrombo-embolic complication, nor death occurred [22]. Moreover, in another series of 200 very old patients (mean age 85.2 years; $G F R=51.2$ $\mathrm{mL} / \mathrm{min}$ ) no plasma accumulation could be detected either, even after 1 month of follow-up, although tinzaparin was given at the full standard therapeutic dose of $175 \mathrm{IU} / \mathrm{kg}$ in approximately $77 \%$ of these patients. Of note, another $7 \%$ of patients received a dose higher than $175 \mathrm{IU} / \mathrm{kg}$ [22]. Only three major bleeding episodes (1.5\%) occurred, two of them being likely due to multidrug interactions. Considering six reported fatal cases, only one $(0.5 \%)$ could be related to the anticoagulant treatment in this fragile population [23].

Doses of LMWH should be adjusted in case of expected accumulation. If not, increased bleeding complications will occur, as has been reported in a meta-analysis of enoxaparinuse, where a fourfold increased relative risk was detected [24].

For this reason, the recent ACCP guidelines argue against the use of anticoagulants that accumulate in patients with renal impairment and recommend monitoring anticoagulant effect (plasma anti-Xa activity) to enable adjustment of the dose in such patients at risk [13]. For very old patients, it should be common clinical practice to accurately adjust the dose to body weight, to regularly monitor platelet counts in a surgical context, to determine anti-Xa levels, and to correctly manage any interaction with other antithrombotic drugs. In their literature overview these guidelines further state that when used in full therapeutic doses, nadroparin clearance, but not tinzaparin clearance, was correlated with creatinine clearance $(\mathrm{R}=0.49 ; \mathrm{p}<0.002)$, even when creatinine clearance was as low as $20 \mathrm{~mL} / \mathrm{min}$ [25]. Guidelines report that enoxaparin (40 mg once daily), but not tinzaparin (4500 Units once daily), bio accumulate over 8 days of exposure [25].

Two major trials have explored the effects of tinzaparin in elderly patients with renal impairment or in patients with cancer. The IRIS trial ( $\mathrm{N}=542$ ) explored elderly patients aged $\geq 75$ years with creatinine clearance $\leq 60 \mathrm{~mL} / \mathrm{min}$ or $\geq 70$ years with creatinine clearance $\leq 30 \mathrm{~mL} /$ $\min$ [23]. Tinzaparin or UFH were given during the first 5 days. Vitamin $\mathrm{K}$ antagonists were given subsequently during 3 months, and clinical effects were evaluated after these 3 months. There were no differences between these two groups regarding clinically relevant bleeding episodes, nor for thrombosis recurrences. There was a non-significant trend towards less symptomatic thrombo-embolic events with heparin, and also surprisingly a lower mortality in UFH treated patients. But baseline characteristics showed an imbalance of some important items between the two groups. There were more traumas, more ongoing malignancy, more cardiac insufficiency, more immobilization and more infectious disease in the group assigned to tinzaparin compared to the group receiving UFH [26]. This introduced, by the play of chance, a potential bias for the interpretation of the results.

The LITE trial explored tinzaparin impact in 200 cancer patients given either tinzaparin or UFH + warfarin during 3 months, followed by 
Citation: Elalamy I, Canon JL, Bols A, Lybaert W, Duck L, et al. (2014) Thrombo-Embolic Events in Cancer Patients with Impaired Renal Function. J Blood Disorders Transf 5: 202. doi: 10.4172/2155-9864.1000202

Page 5 of 5

9 months of usual care [11]. An important fact was that renally impaired patients were only excluded if they required regular hemodialysis. The most important results of the LITE study are depicted in Figure 6 . There was a significant $56 \%$ reduction in thrombo-embolic events among tinzaparin treated patients. A Kaplan-Meyer graph showed a significant difference appearing early during the trial, which further increased over time. The incidence of major bleeding complications was equal between groups [11]. This trial confirms that long-term treatment with LMWHs is more effective than vitamin $\mathrm{K}$ antagonists for preventing recurrent venousthrombo-embolism (VTE) in cancer patients with previous proximal venous thrombosis.

\section{Conclusions}

Cancer patients have an increased risk of venous thrombo-embolic events, which translates in increased morbidity and mortality. Many cancer patients have some form of chronic renal impairment with various co-morbidities or acute renal impairment from their cancer and its treatment. LMWHs have been shown to decrease venous thrombosis risk in cancer patients without increasing major bleeding complications. As such, LMWHs are recommended as first line therapeutic antithrombotic treatment in cancer patients as they give a clear clinical benefit. In patients with renal impairment, who are at increased risk of bleeding as well asthrombotic complications, we propose the use of a higher molecular weight LMWH such as tinzaparin, because it is associated with a lower risk of plasma accumulation and offers the possibility of maintaining the standard therapeutic dose.

\section{Funding Source}

P. Clement received payment from Leo pharma for consultancy

\section{References}

1. Pruemer J (2005) Prevalence, causes, and impact of cancer-associated thrombosis. Am J Health Syst Pharm 62: S4-6.

2. Khorana AA, Francis CW, Culakova E, Kuderer NM, Lyman GH (2007) Frequency, risk factors, and trends for venous thromboembolism among hospitalized cancer patients. Cancer 110: 2339-2346

3. Wun T, White RH (2009) Epidemiology of cancer-related venous thromboembolism. Best Pract Res Clin Haematol 22: 9-23.

4. Lyman GH (2011) Venous thromboembolism in the patient with cancer: focus on burden of disease and benefits of thromboprophylaxis. Cancer 117: 1334-1349.

5. Tsopanoglou NE, Maragoudakis ME (2009) Thrombin's central role in angiogenesis and pathophysiological processes. Eur Cytokine Netw 20: 171-179.

6. Rickles FR (2006) Mechanisms of cancer-induced thrombosis in cancer Pathophysiol Haemost Thromb 35: 103-110.

7. Esmon CT (2009) Basic mechanisms and pathogenesis of venous thrombosis Blood Rev 23: 225-229.

8. Fareed J, Jeske W, Fareed D, Clark M, Wahi R, et al. (2008) Are all low molecular weight heparins equivalent in the management of venous thromboembolism? Clin Appl Thromb Hemost 14: 385-392.

9. Mousa SA (2010) Heparin and low-molecular weight heparins in thrombosis and beyond. Methods Mol Biol 663: 109-132.

10. Gerotziafas GT, Petropoulou AD, Verdy E, Samama MM, Elalamy I (2007) Effect of the anti-factor $\mathrm{Xa}$ and anti-factor Ila activities of low-molecular-weight heparins upon the phases of thrombin generation. J Thromb Haemost 5: 955-962.

11. Hull RD, Pineo GF, Brant RF, Mah AF, Burke N, et al. (2006) Long-term low-molecular-weight heparin versus usual care in proximal-vein thrombosis patients with cancer. Am J Med 119: 1062-1072.

12. Hirsh J, Siragusa S, Cosmi B, Ginsberg JS (1995) Low molecular weight heparins (LMWH) in the treatment of patients with acute venous thromboembolism Thromb Haemost 74: 360-363.

13. Kearon C, Akl EA, Comerota AJ, Prandoni P, Bounameaux H, et al. (2012)
Antithrombotic therapy for VTE disease: Antithrombotic Therapy and Prevention of Thrombosis, 9th ed: American College of Chest Physicians Evidence-Based Clinical Practice Guidelines. Chest 141: e419S-94S.

14. Lyman GH, Khorana AA, Kuderer NM, Lee AY, Arcelus Jl, et al. (2013) Venous thromboembolism prophylaxis and treatment in patients with cancer: American Society of Clinical Oncology clinical practice guideline update. J Clin Oncol 31 2189-2204.

15. Mandalà M, Falanga A, Roila F; ESMO Guidelines Working Group (2011) Management of venous thromboembolism (VTE) in cancer patients: ESMO Clinical Practice Guidelines. Ann Oncol 22: vi85-92.

16. Janus N, Launay-Vacher V, Byloos E, Machiels JP, Duck L, et al. (2010) Cancer and renal insufficiency results of the BIRMA study. Br J Cancer 103 1815-1821.

17. Launay-Vacher V, Oudard S, Janus N, Gligorov J, Pourrat X, et al. (2007) Prevalence of Renal Insufficiency in cancer patients and implications for anticancer drug management: the renal insufficiency and anticancer medications (IRMA) study. Cancer 110: 1376-1384.

18. Johansen K, Balchen T (2013) Tinzaparin and other low-molecular-weight heparins: what is the evidence for differential dependence on renal clearance? Exp Hematol Oncol 2: 21

19. Schmid P, Fischer AG, Wuillemin WA (2009) Low-molecular-weight heparin in patients with renal insufficiency. Swiss Med Wkly 139: 438-452.

20. Crowther M, Lim W (2007) Low molecular weight heparin and bleeding in patients with chronic renal failure. Curr Opin Pulm Med 13: 409-413.

21. Mahé I, Aghassarian M, Drouet L, Bal Dit-Sollier C, Lacut K, et al. (2007) Tinzaparin and enoxaparin given at prophylactic dose for eight days in medical elderly patients with impaired renal function: a comparative pharmacokinetic study. Thromb Haemost 97: 581-586.

22. Siguret V, Pautas E, Février M, Wipff C, Durand-Gasselin B, et al. (2000) Elderly patients treated with tinzaparin (Innohep) administered once daily (175 anti-Xa IU/kg): anti-Xa and anti-Ila activities over 10 days. Thromb Haemost 84: $800-804$

23. Pautas E, Gouin I, Bellot O, Andreux JP, Siguret V (2002) Safety profile of tinzaparin administered once daily at a standard curative dose in two hundred very elderly patients. Drug Saf 25: 725-733.

24. Hoffmann P, Keller F (2012) Increased major bleeding risk in patients with kidney dysfunction receiving enoxaparin: a meta-analysis. Eur J Clin Pharmaco 68: 757-765.

25. Garcia DA, Baglin TP, Weitz JI, Samama MM; American College of Chest Physicians (2012) Parenteral anticoagulants: Antithrombotic Therapy and Prevention of Thrombosis, 9th ed: American College of Chest Physicians Evidence-Based Clinical Practice Guidelines. Chest 141: e24S-43S.

26. Leizorovicz A, Siguret V, Mottier D; Innohep ${ }^{\circledR}$ in Renal Insufficiency Study Steering Committee, Leizorovicz A, Siguret V, et al. (2011) Safety profile of tinzaparin versus subcutaneous unfractionated heparin in elderly patients with impaired renal function treated for acute deep vein thrombosis: the Innohep $B$ in Renal Insufficiency Study (IRIS). Thromb Res 128: 27-34.

Citation: Elalamy I, Canon JL, Bols A, Lybaert W, Duck L, et al. (2014) Thrombo-Embolic Events in Cancer Patients with Impaired Renal Function. J Blood Disorders Transf 5: 202. doi: 10.4172/21559864.1000202 